\title{
La comunicación en el deporte global: los medios y los Juegos Olímpicos de verano (1894-2012)
}

\author{
Emilio FERNÁNDEZ PEÑa \\ Universidad Autónoma de Barcelona \\ Emilio.fernandez@uab.cat \\ Natividad RAMAJO HERNÁNDEZ \\ Universidad Autónoma de Barcelona \\ Natividad.ramajo@uab.cat
}

\begin{abstract}
Resumen:
La historia de los Juegos Olímpicos adquiere una nueva perspectiva cuando se analiza desde el ángulo de los medios y los avances tecnológicos. Este artículo se propone estudiar la narrativa oficial del Comité Internacional Olímpico (CIO) en relación con los medios y las tecnologías de la comunicación desde su misma fundación. Ello nos permite proponer una nueva cronología de los Juegos Olímpicos centrada en la comunicación y un análisis sistémico de las políticas de comunicación del Comité Internación Olímpico. La historia de los medios y la tecnología presentada por el CIO es una historia fabricada a través de acontecimientos de éxito, una historia de las primeras veces en las que una nueva tecnología fue puesta en funcionamiento. Es el discurso de los ingenieros y el personal de marketing. El Olimpismo moderno está incardinado en dos mundos: el mundo de los símbolos y los ritos que está presente en la ceremonia de apertura de los Juegos o en la celebración de la victoria por los campeones y el de la esfera posmoderna en la que existe una preeminencia del marketing, una perspectiva funcionalista y utilitarista de un mundo deshumanizado y desconectado del universo animado de los orígenes.
\end{abstract}

Palabras clave: Juegos Olímpicos; medios; comunicación; historia; tecnología; narrativa

\section{Comunication in the global sport: Media and the Summer Olympic Game} (1894-2012)

\begin{abstract}
:
The Olympic Games' history acquires a new perspective when it is analyzed from the media and technological advances angle. This article aims to deepen in the official narratives regarding media and communications technology by the International Olympic Committee (IOC) since its very foundation. Guided by this institutional discourse a chronology of the Games and the communication is proposed. At the same time, the systemic running of the IOC media policy is studied. The history of the media and technology presented by the IOC is a history made of milestones of success, a history of first times, when a new technology was implemented. It is a discourse of engineers and the marketing staff. Olympism is integrated into two worlds: the symbols' and rituals' one which is present in the Opening Ceremony of the Games and the celebration of the victory of the champions and the postmodern sphere with a preeminence of the marketing and a functionalistic and utilitarian aim, a world dehumanized and disconnected from the original purpose and Spirit of the first modern Olympics.
\end{abstract}

Key Words: Olympic Games; media; communication; history; technology, narratives 


\section{Referencia normalizada:}

Fernández Peña, E. y Ramajo Hernández, N. (2014): La comunicación en el deporte global: los medios y los Juegos Olímpicos de verano (1894-2012). Historia y Comunicación Social. Vol. 19. Núm. Especial Marzo. Págs. 703-714.

Sumario: 1. Introducción. 2. Metodología. 3. Los medios que moldearon los Juegos. 3.1. El protagonismo de los medios en el impulso del Movimiento Olímpico moderno (1894-1932). 3.2. Televisión e internacionalización mediática de los Juegos (1936-1960). 3.3. Los Juegos Olímpicos globales (19641992). 3.4. Internet, la web social y la comercialización de los Juegos (1996-2012). 4. La televisión en el discurso de Samaranch y Rogge. 5. La estructura de la narrativa del CIO sobre la tecnología de los medios. 6. Conclusiones. 7. Referencias bibliográficas

\section{Introducción}

Los Juegos Olímpicos son el mayor acontecimiento deportivo a escala global (Berstein, 2000), capaz de reunir ante el televisor a miles de millones de personas de los cinco continentes en torno a la idea del deporte (Tolimson, 1996). También son un evento local que gracias al concurso de los medios muta en un evento global (Moragas et al., 1995). Un acontecimiento deportivo que transforma las ciudades desde diversos ámbitos, aparentemente ajenos al deportivo, y en la organización del cual se invierten decenas de miles de millones de euros: ejemplos de ello son las infraestructuras viarias y de transporte público, la creación de barrios o la mejora de las redes de saneamiento (Moragas, 1996).

El congreso para el restablecimiento de los Juegos Olímpicos celebrado en la Universidad de la Sorbona en junio de 1894 y promovido por Pierre de Coubertin decidió celebrar los primeros Juegos Olímpicos Modernos dos años después en Atenas y constituir el Comité Olímpico Internacional (Müller, 1994). A partir de ese momento se generan unos elementos culturales y educativos que se resumen en los principios fundamentales del Olimpismo, recogidos en la Carta Olímpica:

El Olimpismo es una filosofía de la vida, que exalta y combina en un conjunto armónico las cualidades del cuerpo, la voluntad y el espíritu. Al asociar el deporte con la cultura y la formación, el Olimpismo se propone crear un estilo de vida basado en la alegría del esfuerzo, el valor educativo del buen ejemplo y el respeto por los principios éticos fundamentales universales. El objetivo del Olimpismo es poner siempre el deporte al servicio del desarrollo armónico del hombre, con el fin de favorecer el establecimiento de una sociedad pacífica y comprometida con el mantenimiento de la dignidad humana (CIO, 2013:6).

En opinión de Sigmund Loland, desde la perspectiva de las ideas, el Olimpismo tiene tres metas básicas: educar a la persona a través del deporte, cultivar las relacio- 
nes de las personas en la sociedad y, finalmente, promover la paz y el entendimiento mutuo (Loland, 2010).

En este entramado que constituyen los Juegos y su relación con la sociedad, los medios, en general, y la televisión, en particular, tienen un doble papel relevante: son los financiadores principales del Movimiento Olímpico y de los Juegos y, al mismo tiempo, son los transmisores destacados de su sistema de valores (Moragas et al., 1995), (Fernández et al., 2011).

En el presente trabajo miraremos a la historia del Olimpismo desde la perspectiva de los medios y los avances tecnológicos en materia de comunicación. Analizaremos cómo el Comité Internacional Olímpico ha construido un discurso institucional con la trascendencia mediática y la innovación tecnológica como protagonistas de los Juegos Olímpicos, lo que nos permitirá proponer una cronología de los Juegos Olímpicos de verano con la comunicación como centro, profundizando de este modo en el papel de los medios en relación con los Juegos.

\section{Metodología}

Este trabajo está basado metodológicamente en la revisión y el estudio de las memorias oficiales de los Juegos Olímpicos de verano desde Atenas 1896 a Londres 2012, los documentos de marketing oficiales, las publicaciones oficiales y catálogos de exposición del Museo Olímpico, los contenidos oficiales de la página web del Comité Internacional Olímpico, así como los libros y artículos publicados en español e inglés sobre la temática.

El trabajo sigue un método histórico, pero aspira a desentrañar la complejidad inherente a los procesos de comunicación institucional de una organización como el Comité Internacional Olímpico y exponer la estructura de su forma narrativa.

\section{Los medios que moldearon los juegos}

El trabajo cronológico realizado en este artículo bebe de las narraciones institucionales del Comité Internacional Olímpico en cualquiera de sus formatos. Ejemplos de ello son los innumerables informes de marketing existentes o las secciones de historia del Olimpismo ofrecidas en la página web del Comité Internacional Olímpico (Olimpic.org). Por lo tanto, basándonos en todos esas publicaciones oficiales y centrándonos en el papel de los medios y en las nuevas tecnologías de telecomunicaciones audiovisual proponemos la siguiente cronología.

En primer lugar, el protagonismo de los medios en la creación del Movimiento Olímpico moderno (1894-1932); a continuación, la televisión y la internacionali- 
zación mediática de los Juegos (1936-1960); en tercer lugar, los Juegos Olímpicos globales (1964-1992); para terminar con internet, la web social y la comercialización de los Juegos (1996-2012).

3.1. El protagonismo de los medios en el impulso del movimiento olímpico moderno (1894-1932)

Hay relaciones que con el paso del tiempo se presentan ante nuestros ojos como un hecho indisoluble, firmemente unido, en una especie de simbiosis absoluta. Esto es lo que ha ocurrido desde sus inicios con el Olimpismo moderno y los medios de comunicación. Sería prácticamente imposible comprender el fenómeno mundial en el que han devenido los Juegos sin el concurso de los medios desde el primer momento (Fernández et al., 2011). Las reflexiones teóricas, la labor pedagógica de Pierre de Coubertin (Müller, 2012) y la celebración propiamente dicha de los Juegos Olímpicos tienen el apoyo de los medios como soportes y difusores de la iniciativa. Durante la celebración del primer congreso Olímpico, el germen de los futuros Juegos, Coubertin (1894) llama rebeldes a todos los allí reunidos por sus intentos de romper con las anquilosadas dinámicas de la vieja academia. Significativo es que en esa misma intervención, Pierre de Coubertin agradezca a la prensa todo el apoyo prestado: "we are rebels and that is why the press which has always supported beneficent revolutions has understood and helped us - for which, by the way, I thank it with all my heart" (Coubertin, 1894: 394).

Sin lugar a dudas, una de las principales manifestaciones de esa unión entre los medios y la promoción de los Juegos surge aparejada al nacimiento de la primera tecnología capaz de registrar y reproducir imágenes en movimiento, el cinematógrafo (1895). Con él se sientan las bases del posterior lenguaje y modos de expresión de la televisión. Durante las primeras ediciones de los Juegos, a pesar de que la tecnología ya existía, no se han conservado pruebas gráficas de los mismos. Sí se llegaron a registrar imágenes de los segundos Juegos, los de París en 1900, pero el

Comité Olímpico Internacional no dispone de ellas (Llinés y Moreno, 1999: 15-17).

Tendríamos que esperar a Londres 1908 para tener ese documento gráfico en movimiento de unos Juegos Olímpicos. Concretamente, se trata del lanzamiento de disco de Martin Sherindan y de la prueba de salto de altura de George Andre (CIO, 2013). Cuatro años más tarde, en Estocolmo 1912, se filma la primera película de los Juegos como evento deportivo. Un extracto de 24 vídeos de corta duración se puede consultar en la página web del Comité Olímpico Internacional.

En estas algo más de tres décadas iniciales de historia olímpica, la radio es el otro medio audiovisual que contribuye a la difusión de los Juegos, y lo hace básicamente a partir de los Juegos Olímpicos de 1936, aunque en Ámsterdam 1928 y Los Ángeles 1932 ya existieran retransmisiones radiofónicas. Los motivos de ese retraso en la masificación de las emisiones radiofónicas (hay que tener en cuenta que en los primeros años 20 ya habían comenzado sus emisiones en varios países) hay que buscarlos en cuestiones de carácter técnico y de índole económica. Un ejemplo de 
esas carencias técnicas es la inexistencia de cables transoceánicos y de una tecnología de emisión desarrollada para largas distancias. El segundo motivo, y tal vez el más importante, fue la presión de los editores de periódicos en el Reino Unido y de los estudios de Hollywood, junto a las restricciones del comité Organizador, temerosos de que la presencia en directo de la radio restase peso a la venta de entradas, fuente de ingresos de altísimo valor en aquellos años (McVoy, 1997; Llinés y Moreno, 1999).

\subsection{Televisión e internacionalización mediática de los juegos (1936-1960)}

Los Juegos Olímpicos de Berlín en 1936 están archivados en la memoria colectiva por imágenes y situaciones que sobrepasaron el ámbito deportivo. Pero, también son los Juegos que marcaron el inicio de la era de la televisión y su vinculación con el Movimiento Olímpico. Es la primera vez que se realiza una retransmisión a través de circuito cerrado a 21 auditorios situados en Berlín, Potsdam y Leipzip. Esta primera retransmisión se hace con tan sólo tres cámaras y la experiencia social resultante es muy similar a la del cinematógrafo: es un visionado colectivo de la nueva tecnología. Sin embargo, ya podemos afirmar que asistimos al inicio de las telecomunicaciones al intervenir en el proceso el envío de imágenes a distancia a través de ondas hertzianas. Se había inventado la tecnología, que indudablemente debía ser perfeccionada, aunque los usos sociales del medio no se asentarán hasta más de dos décadas después.

En estos mismos años de los Juegos de Berlín, hay que destacar otra aportación importante al Movimiento Olímpico, fruto del avance de los medios audiovisuales y de sus narrativas. Nos estamos refiriendo a la película Olimpia (1938) de la realizadora alemana Leni Riefenstahl. En este documental cinematográfico se aprecian valiosísimas innovaciones de expresión audiovisual que serán utilizadas más tarde por la televisión y que con el tiempo se convertirán en estándares de las retransmisiones deportivas: ejemplos de ello son la colocación de cámaras cenitales, el uso de la cámara lenta y de cámaras que en su movimiento siguen la progresión de los deportistas.

Cuando los Juegos vuelven a recuperar su protagonismo tras la interrupción sufrida por la Segunda Guerra Mundial, se observa que la televisión adquiere una nueva dimensión en el desarrollo del Movimiento Olímpico. No sólo se trata de las mejoras que conlleva el avance tecnológico, sino que también el medio se convierte por primera vez en una fuente de ingresos para el Olimpismo que en sucesivas citas olímpicas pasará a ser fundamental. En este sentido, en Londres 1948 se retransmiten los Juegos a través de ondas hertzianas a un reducido ámbito alrededor del estadio Olímpico, de tan sólo 50 millas. La televisión ya podía ser consumida desde los hogares, aunque todavía eran pocos los británicos que disponían del aparato (se calcula que unos 80.000 hogares). Ese año, la BBC pagó por primera vez en la historia 80.000 guineas por poder retransmitir los Juegos.

Una década más tarde, es Italia la que se convierte en el centro del Olimpismo. Los Juegos de invierno de Cortina d'Ampezzo son los primeros en ser retransmitidos por televisión. En 1960, en los Juegos de Roma, las retransmisiones pasan a ser 
internacionales. En total, 18 países europeos recibieron las señales en directo a través de Eurovisión y esos mismos Juegos pudieron verse en diferido en Estados Unidos, Canadá y Japón, sólo unas pocas horas después. Los Juegos de Roma también pasarán a la historia por otra gran aportación: el uso del magnetoscopio que permite grabar y reproducir, dando la posibilidad al emisor, pero también al receptor, de revivir las experiencias una y otra vez.

\subsection{Los juegos olímpicos globales (1964-1992)}

El hecho de que la tecnología audiovisual avance de forma vertiginosa entre la realización de unos Juegos y los siguientes hace que el fenómeno Olímpico se convierta poco a poco en una expresión deportiva global, compartida por millones de personas. A partir de estos años son innumerables los avances técnicos en el campo televisivo. Por ejemplo, en Tokio 1964 se produce la primera retransmisión por satélite de los Juegos, un primer paso hacia esa globalidad. Durante estos Juegos también se realizaron las primeras experiencias de televisión en color y de repetición en cámara lenta, gracias al desarrollo de los sistemas de grabación con magnetoscopios, ya iniciada en los Juegos de Roma. En Munich 1972 los avances en la tecnología permiten tener cámaras más ligeras y de menor tamaño.

Con la llegada de Juan Antonio Samaranch en 1980 al CIO se inaugura una nueva forma de concebir la relación entre la familia Olímpica y los medios audiovisuales: se apuesta por la comercialización masiva de los Juegos Olímpicos mediante el aumento de los derechos televisivos a través de la televisión norteamericana. Para imprimir estabilidad a los ingresos, independientemente de la ciudad de celebración, Samaranch decide negociar acuerdos a largo plazo y, siempre que fuera posible, antes de que se supiese el nombre de la ciudad organizadora de los Juegos (Fernández, 2009b).

Siguiendo el impulso de los avances tecnológicos, en estos años se introducen cámaras robóticas que posibilitan nuevos planos, más cercanos a los deportistas, ayudando de este modo a transmitir las emociones con mayor intensidad y a enriquecer con nuevas perspectivas la creación audiovisual del deporte para la televisión (Fernández, 2013). En Los Ángeles 1984 se usa la fibra óptica para transmitir la señal desde el lugar en que se desarrolla el acontecimiento deportivo al centro de control de televisión y en Barcelona 1992 se utilizan vídeos digitales y se introduce por primera vez la alta definición.

\subsection{Internet, la web social y la comercialización de los juegos (1996-2012)}

Desde el inicio de los Juegos Olímpicos de la era moderna han sido incontables los avances tecnológicos que han marcado, de una u otra forma, las relaciones entre medios y Movimiento Olímpico. Sin lugar a dudas, en esta cronología tecnológica, el nacimiento de la World Wide Web en 1993 es un nuevo punto de inflexión. Los Juegos de Barcelona no pudieron beneficiarse de las posibilidades de la web, pero en Atlanta 1996 se ofrece una página web con resultados deportivos e información útil que recibe 185 millones de visitas durante esos Juegos (Fernández et al., 2011). 
El Comité Olímpico Internacional había creado su página web un año antes. Sin embargo, no será hasta los Juegos de Atenas en 2004 cuando la cadena norteamericana NBC empiece a ofrecer a través de su página web resúmenes de las competiciones y clips de vídeo. El mandato de Rogge, sucesor de Juan Antonio Samaranch a partir de julio de 2001, se caracteriza por la promoción de la competencia en la pugna por los derechos televisivos (Payne, 2006) y la vuelta de los consultores y asesores a Laussane, ante la situación de enorme complejidad en el ámbito de la competencia, sobre todo en el caso de un mercado norteamericano con cinco networks en liza. También es el mandato en el que las televisiones apuestan por la promoción de los valores Olímpicos y sus símbolos. Un compromiso que aporta un valor cualitativo en la competición por la adquisición de los derechos audiovisuales.

Siguiendo dentro del terreno económico, estos también son los años de la masificación del fenómeno de la esponsorización vinculado a la televisión: NBC ofrece en la negociación de 2003 la entrada de su accionista General Electric como TOP Sponsor con una propuesta de 200 millones de euros hasta 2012 (Payne, 2006: 63). También son momentos de máxima cobertura televisiva, fruto de la adaptación al entorno multicanal de los grandes grupos multimedia, combinando las retransmisiones de los canales generalistas con otras en canales especializados en deportes. En concreto, la cadena norteamericana NBC llega a utilizar nueve canales de televisión diferentes para la retransmisión de las ceremonias y las distintas pruebas deportivas: NBC, CNBC, MSNBC, USA, Telemundo (en español), Universal HD, Oxygen, y dos nuevos canales multiplexados digitales de la propia NBC que en ocasiones ofrecían la misma programación durante diferentes momentos del día.

Otro momento destacable es el vivido en los Juegos de Pekín 2008, donde gracias al acuerdo con Youtube, el Comité Olímpico Internacional ofrece la retransmisión en abierto de todos los Juegos a través de esta plataforma a 78 países de África y Asia, países en los que ningún broadcaster había mostrado interés a la hora de comprar los derechos audiovisuales (Fernández, 2009a). Son también los Juegos de la primera retransmisión totalmente en alta definición. En Vancouver 2010 la familia Olímpica se estrena en las redes sociales, inaugurando sus páginas en Facebook y Twitter. Finalmente, Londres 2012 se convierten en los Juegos de la consolidación de las posibilidades de las redes sociales y la creación del llamado Hub de deportista (CIO, 2012) que centraliza las presencias en Facebook y Twitter de todos los competidores en los Juegos. Desde el punto de vista televisivo, los Juegos de Londres son los primeros retransmitidos en $3 \mathrm{D}$.

La estrategia de comunicación en redes sociales ha revelado una forma de entender la comunicación a través de los diferentes medios por parte del Comité Olímpico Internacional no sistémica (Fernández, Ramajo y Aráuz, 2014). El CIO no promueve la interrelación entre las diferentes presencias para que funcionen de forma combinada y se puedan aprovechar las sinergias entre ellas. Durante los Juegos Olímpicos de Vancouver, cada presencia en las redes sociales era administrada y concebida de forma individualizada (Fernández et al., 2011), si bien esa estrategia se varió en los Juegos de Londres, gracias al ya mencionado Hub del deportista que centralizaba la 
presencia de los deportistas en las redes sociales, facilitando su consulta y seguimiento por parte de los aficionados, pero también permitió al CIO realizar un control organizado sobre lo que los deportistas publicaban, monitorizando si seguían los preceptos de la Carta Olímpica (Fernández, Ramajo y Aráuz, 2014). A pesar de ello, las redes sociales para el CIO no dejan de ser en estos momentos una estrategia marginal y no debidamente incardinada en la estrategia de comunicación de la organización.

\section{La televisión en el discurso de Samaranch y Rogge}

El presidente del Comité Olímpico Internacional Juan Antonio Samarach (19802001) fue el responsable del sistema de comercialización de los Juegos Olímpicos, entre otras cuestiones con la valorización y venta de los derechos audiovisuales y la creación de programas globales de esponsorización (los llamados TOP Sponsor Program ) de indudable éxito económico, mientras que su sucesor, Jaques Rogge (2001-2013), siguió la senda marcada por Samarach con algunos cambios como la apertura a los operadores de televisión privados en Europa o la venta de derechos audiovisuales en países poco poblados a empresas de medios (Fernández, 2009b). Ambos, proyectan una visión similar del papel de las televisiones.

Para Samaranch, los Juegos de Barcelona y Albertville en 1992 fueron los de mayor interés en la historia Olímpica, fruto, precisamente, de la amplia cobertura televisiva que recibieron, siendo "a través de la televisión por la que el mundo experimenta los Juegos" (Tolimson, 1996: 583), mientras que Rogge subraya el carácter global de los Juegos y cómo la necesidad de incrementar el número de espectadores no pasa por aumentar la capacidad de los estadios, sino por la televisión (Barney, Wenn y Martyn, 2002).

Estas dos visiones muy similares del papel decisivo de la televisión en la creación del fenómeno global que constituyen los Juegos tienen dos finalidades. Por una parte, subrayar el hecho incontrovertible de su extraordinario alcance mundial gracias al concurso de los medios. Por la otra, dirigir un mensaje a los propietarios de los derechos televisivos y a las empresas patrocinadoras globales, una forma de comunicarles que su inversión es rentable.

\section{La estructura de la narrativa del cio sobre la tecnología de los medios}

Para Molinuevo (2004), "el drama hoy de la caverna digital es que tampoco somos capaces de conocerla porque no la reconocemos. Vivimos en un mundo de imágenes sin saberlo. Porque, después de Platón, la civilización occidental ha sido educada escolar y académicamente en un mundo de esencia y no de apariencias. Pero la educación sentimental, fuera de ese ámbito, hace tiempo que consiste básicamente en 
una educación en las imágenes. Hace tiempo ya que quien educa es la palabra, pero quien forma es la imagen" (Molinuevo, 2004: 22 y 23). Sin embargo, todo parece indicar que en las sociedades actuales las imágenes ofrecidas por los medios tienen un poder mucho mayor que el otorgado por Molinuevo. Desafortunadamente, con la palabra se educa mucho menos de lo que Molinuevo postula. Los medios, desde una perspectiva banalizadora y simplificadora de una realidad cada vez más compleja, han contribuido como un elemento más a la ruptura del canon educativo occidental humanístico, tal y como señala Sloterdijk (2006).

En el mundo actual toda organización ha de construir su propia narrativa, no sólo de cara al mundo exterior, sino también de cara al interior de la institución. La construcción del storytelling, de las historias sobre los éxitos de las organizaciones, de los gobiernos y de los individuos, se ha erigido en una necesidad básica en nuestros días. En las sociedades actuales con omnipresencia mediática, en las que las apariencias, la realidad mediada, son más importante que la propia realidad (Verdú, 2003), incluso en las que se confunden realidad, apariencia y simulacro (Baudrillard, 2005) no es sólo necesario alcanzar el éxito, sino que constituye una necesidad vital contarlo adecuadamente al mundo. En este sentido, Baudrillard evoluciona hacia una visión extrema de la nueva sociedad implementada por los medios y la virtualización: "the saturation of the world, the technical saturation of life, the excess of possibilities, of actualization of needs and desires, how are we to believe in reality once its production has become automatic" (Baudrillard, 2005: 19). Una visión pesimista de las distintas mutaciones fruto de la técnica que lleva del poder de los símbolos a la eliminación de la realidad y su sustitución por una realidad virtual en la que la sustancia simbólica ha sido aniquilada y cambiada por una realidad de hechos, un universo positivo desencantado, un mundo que es "as factual as ready-made"(Baudrillard, 2005: 25).

La visión institucional de los medios del Comité Olímpico Internacional se moldea a través de los informes de las diferentes ediciones de los Juegos, en primera instancia, y de las más recientes publicaciones de marketing, en las que se explica el papel de las televisiones en la difusión de los Juegos, su financiación y la distribución de los ingresos, entre otras cuestiones. Es un conjunto de ítems que acompaña esos documentos de marketing y aquellos destinados a los medios de comunicación y que también está presente en su página web, Olympic.org.

Esta visión institucional, igualmente se ha vertido en exposiciones mostradas en el Museo Olímpico, como la titulada "Broadcasting the Olympics" (1998), organizada en Lausana entre el 20 de octubre de 1998 y el 18 de abril de 1999. Es una visión de la evolución de las tecnologías de la televisión que se centra también en hitos y explica el funcionamiento técnico de los nuevos aparatos: las tecnologías de telecomunicaciones, de grabación, de almacenaje y de distribución. Más adelante se detiene en las novedades tecnológicas introducidas en cada edición de los Juegos Olímpicos. 


\section{Conclusiones}

A la luz de lo expuesto, todo parece indicar que el discurso de los ingenieros y de los centros de marketing se postula en cada una de las manifestaciones institucionales del Comité Olímpico Internacional: publicaciones de marketing, exposiciones sobre la televisión en el Museo Olímpico y diversas secciones de la página web. También da la sensación de que estuviese influido a su vez por el lenguaje deportivo de la superación, pues se centra en la narrativa de las primeras veces, en la que el carácter pionero de los Juegos en la introducción de nuevas tecnologías, destila esa aspiración deportiva de ser los primeros en alcanzar la meta y la gloria. Finalmente, este enfoque utilitarista y pragmático que moldea las publicaciones oficiales del CIO en poco se diferencia del discurso oficial de una organización empresarial global cualquiera.

El Olimpismo moderno parece vivir entre dos mundos. Por un lado, sus símbolos y ritos, ejemplo de los cuales es el fuego que se enciende en Olimpia con la luz del sol y se traslada a la ciudad organizadora de los Juegos o los ritos de homenaje a los campeones en la entrega de medallas, vinculándonos a ese pasado pre-artesano, en el que existe una continuidad entre el microcosmos del hombre y el macrocosmos del universo. Por otro lado, el marketing, la tecnología de creación y distribución audiovisual que nos hace sentirnos próximos a la modernidad postindustrial y deshumanizada. En el discurso oficial domina, de momento, la visión moderna, aunque el sustrato simbólico, ritual y de los valores positivos del deporte olímpico mantienen la esperanza de una humanización que quizás esté por llegar.

\section{Bibliografía}

BARNEY, R.; WENN, S. R.; MARTYN, S. G. (2002). Selling the Five Rings: The International Olympic Committe and the Rise of Olympic Commercialism. Salt Lake City: The University of Utah Press.

BAUDRILLARD, J. (2005). The intelligence of evil of the lucidity pact. New York: Berg.

COMITÉ OLÍMPICO INTERNCIONAL (1999). Broadcasting the Olympics. Diffusion des Jeux Olympiques. Lausana: IOC.

(2012). London Olympic Games Marketing:Media Guide. Lausana: IOC.

FERNÁNDEZ, E. (2009a). Beijing Olympic Games: Mass media and the role of the internet. [Lecture in the 49th Session for Young Participants]. Olympia, Greece: International Olympic Academy.

(2013). "Chronology of Media and the Olympic Games". Permanent Exhibition. Olympic Museum. Laussane: Comité Olímpico Internacional.

FERNÁNDEZ, E.; RAMAJO, N.;ARÁUZ, M. (2014). "Social Media in the Olympic Games: Actors, Management and Participation". En, BILLINGS, A.; HARDIN, M. (eds.) (2014). Handbook of Sport and New Media. New York: Routledge. 
FERNÁNDEZ, E. (et al.) (eds.) (2011). An Olympic Mosaic: Multidisciplinary Research and Dissemination of Olympic Studies. CEO-UAB: 20 Years. Barcelona: CEO-UAB y Ajuntament de Barcelona.

LLINÉS, M.; MORENO, A. B. (1999). "The History of Radio and Television coverage of the Olympic Games". En Televisión in the Olympic Games. The New Era. International Symposium. Lausana: IOC.

LOLAND, S. (2010). "Coubertin's ideology of Olympism the perspective of the History of Ideas". En, BARNEY, R. K. (ed.) (2010). Rethinking the Olympics: Cultural Histries of the Modern Games. Morgantwon: West Virginia University.

McVOY, J. (1997). "Radio Sports Broadcasting in the United States, Britain and Australia, 1929-1956 and its influence on the Olympic Games". En: Journal on Olympic History. Vol.5 No 1.

MORAGAS, M. (1996). Las Claves del éxito: Impactos sociales, deportivos, económicos y Comunicativos de Barcelona 92. Barcelona: CEO-UAB.

MORAGAS, M.; RIVERBURGH, N. K.; LARSON, J. F. (1995). Television in the Olympics. Londres: John Libbey.

MOLINUEVO, J. L. (2004). Humanismo y Nuevas Tecnologías. Madrid: Alianza.

MÜLLER, N. (1994). One Hundred Years of Olympic Congresses 1894-1994. Laussane: International Olympic Committee.

MÜLLER, N. (2012). Pierre de Coubertin (1863-1937). Olimpismo. Selección de Textos. Lausana: Comité Internacional Pierre de Coubertin.

PAYNE, M. (2006). Olympics Turnaround. EE.UU: Greenwood Publishing Group.

TOLIMSON, A. (1996). "Olympic spectacle: opening ceremonies and some paradoxes of globalization". En: Media, Culture \& Society. Vol. 18. London: Sage. p. 583-602.

SLOTERDIJK, P. (2006). Normas para el parque humano. Una respuesta a la carta sobre el humanismo de Heidegger. Madrid: Siruela.

VERDÚ, V. (2003). El Estilo del Mundo: La vida en el capitalismo de ficción. Barcelona: Anagrama.

7.1 Artículos en publicaciones web

COMITÉ OLÍMPICO INTERNCIONAL (2013). Olympic.org. Videos. Disponible en: http://www.olympic.org/videos/london-1908-martin-sheridan. [20-7-2013].

COUBERTIN, P. (1894). "Speech by Baron Pierre de Coubertin at the Paris Congress held at the Sorbonne 16th-23rd JUNE 1894". Disponible en: http://library.la84. org/OlympicInformationCenter/OlympicReview/1969/ore22/ore22n.pdf. [19-72013].

FERNÁNDEZ, E. (2009b). "Juegos Olímpicos de Verano y derechos audiovisuales. Evolución y retos en el entorno New Media". En: Revista Latina de Comunicación Social, 64. Universidad de La Laguna. Tenerife. Disponible en http://www.revistalatinacs.org/09/art/876_Barcelona/77_144_Fernandez.html. [12-9-2013]. 


\section{Los autores}

Emilio Fernández Peña es profesor Titular de Comunicación Audiovisual y Publicidad de la UAB y director del Centre d'Estudis Olímpics i de l'Esport de la Universidad Autónoma de Barcelona. También es miembro del grupo de investigación consolidado de la UAB, GRISS (Grup de Recerca en Imatge, So i Síntesi). Entre sus investigaciones más destacadas se encuentra el proyecto sobre Redes Sociales y Olimpismo, por encargo del Comité Olímpico Internacional. También ha sido consultor a cargo del concepto y el guión de la exhibición permanente sobre Televisión y Juegos Olímpicos del Museo Olímpico del Comité Olímpico Internacional en Lausana. Emilio Fernández es director del módulo sobre Medios y Comercialización del Master of Art on Olympic Studies, en el que participan cuatro universidades europeas. Es autor de más de 35 publicaciones en los ámbitos del Olimpismo, deporte y derechos audiovisuales, historia de la televisión de pago, además de otros ámbitos. Ha sido invitado como conferenciante y profesor en varias universidades de Estados Unidos, China, Corea del Sur, Qatar, Brasil, Grecia, Italia y Rusia.

Natividad Ramajo Hernández es profesora Titular de Comunicación Audiovisual y Publicidad de la UAB y miembro del Centre d'Estudis Olímpics i de l'Esport de la Universidad Autónoma de Barcelona. En la actualidad es subdirectora de Docencia y Profesorado del Departamento de Comunicación Audiovisual y Publicidad de la UAB. También es miembro del grupo de investigación consolidado de la UAB, GRISS (Grup de Recerca en Imatge, So i Síntesi). Su actividad investigadora en los últimos años se ha centrado en tres ámbitos. El primero de ellos es el referido a la promoción de la participación de los públicos en los nuevos medios. El segundo de ellos es el relacionado con el deporte, el olimpismo y el género. Finalmente, destacar que también ha centrado su actividad investigadora en la interacción del público adolescente con los medios audiovisuales. Es autora de más de 20 contribuciones en éstos y otros ámbitos de la investigación en comunicación. 